\title{
Multiple Myeloma with Suspected Non-Secretory Type
}

\author{
Annisa Ginar Indrarsi, Usi Sukorini \\ Department of Clinical Pathology and Laboratory Medicine, Faculty of Medicine, Gajah Mada University/Dr. Sardjito Hospital, Yogyakarta, \\ Indonesia.E-mail: annisa.indrarsi@gmail.com
}

\begin{abstract}
Multiple Myeloma (MM) is a hematological malignancy characterized by clonal plasma cell in bone marrow that produce abnormal globulin, which resulted in monoclonal gammopathy. Multiple Myeloma Non-Secretory (MMNS) is a very rare form of multiple myeloma with monoclonal plasmocytic proliferation in bone marrow supported by clinical manifestation and radiological findings. However, plasma cells fail to secrete immunoglobulin. A 44-year-old female came to Sardjito General Hospital with main complaints of weakness and back pain. General weakness and pale palpebral conjunctiva were observed (+/+), liver and spleen were not palpable. Blood test results were as follows: $\mathrm{Hb} 3.0 \mathrm{~g} / \mathrm{dL}, \mathrm{RBC} 1.07 \times 10^{6} / \mu \mathrm{L}, \mathrm{WBC}$ $562 \times 10^{3} / \mu \mathrm{L}, \mathrm{PLT} 114 \times 10^{3} / \mu \mathrm{L}, \mathrm{A} / \mathrm{G}$ ratio 1.07, BUN $51.5 \mathrm{mg} / \mathrm{dL}$, creatinine $4.62 \mathrm{mg} / \mathrm{dL}$, and calcium $3.1 \mathrm{mmol} / \mathrm{L}$. Skeletal survey suggested a multiple osteolytic. Protein electrophoresis revealed hypogammaglobulinemia with no M-spike. There were $66 \%$ of plasma cells in bone marrow. Patient was diagnosed by MMNS. Diagnosis MMNS can be established if clonal plasmacytes is accompanied with renal insufficiency and hypercalcemia. However, monoclonal gammopathy was not found in serum protein electrophoresis. A case reported of 44-year-old female diagnosed as MMNS with 'punched out' multiple osteolytic, increased plasma cells in bone marrow without evidence of paraprotein in circulation proved by low $A / G$ ratio and negative M-spike.
\end{abstract}

Keyword: Multiple myeloma non-secretory, hypogammaglobulinemia

\section{INTRODUCTION}

Multiple Myeloma (MM) is a proliferation of malignant plasma cells in the bone marrow, characterized by the presence of clonal plasma cells in the bone marrow that typically secrete an abnormal immunoglobulin causing monoclonal gammopathy. ${ }^{1}$ The incidence of MM is $10 \%$ of hematological malignancies, with an incidence of 5.5 cases of 100,000 population. The median age at diagnosis is 70 years and only $3.4 \%$ of cases are diagnosed between the ages of 35-44 years. ${ }^{2}$

Incidence of $\mathrm{MM}$ in Indonesia is still not widely reported. In 2005, the Clinical Pathology Department of University of Sumatera Utara/Adam Malik General Hospital and Tembakau Deli Medan Hospital reported 10 cases of multiple myeloma over the past 15 years. ${ }^{3}$

Multiple Myeloma Non-Secretory (MMNS) ranged between $1-5 \%$ of MM cases. ${ }^{4}$ This neoplasm is a rare clinical form of multiple myeloma, which is characterized by absence of monoclonal protein in serum or urine. ${ }^{5}$ The following was a rare case of MMNS in 44-year-old female. There was no monoclonal gammopathy found in serum, skeletal survey showed multiple osteolytic, plasmacytosis was found in bone marrow aspiration. This case reported by considering it case is rare and difficult to diagnose because of the atypical laboratory finding for $\mathrm{MM}$ and also because of the relatively young age of its patients.

\section{CASE}

A 44-year-old female was admitted to the hospital with weakness of both limb, fever, dan back pain since the first day before hospitalization. The history of diasease was seven months before admitted to the hospital, patient's complaint of buttocks pain disappeared, but complaint got worse with bump appeared behind the ear. There were no limb weakness, nausea, and vomiting. Four months before admitted to the hospital, the pain became increasingly worse and was felt more often, especially when the position was changed. In addition, a complaint was also accompanied by sensation of heavy legs, although both legs were still able to be lifted but not strong enough to walk. The patient was taken to general practitioners and given medicine to reduce the pain. Two months before admitted to the hospital, the patient felt weak, pale, easy fatigue when doing some activity, no shortness 
of breath, decreased appetite, nausea, and no vomiting. No bleeding and no complaint was found in the defecation and urinary process. The day when patient was admitted to the Ludira Husada Hospital, she complained weakness, paleness, weakness both of limb, fever, back pain, and cough. When the electrocardiography heart rate was 160x/minute, patient was referred to Sardjito general hospital.

The general status was weak. The vital sign examinations were as follow: GCS $4-5-6$, blood pressure $100 / 60 \mathrm{mmHg}$, pulse rate 121 times/min with weak pressure, respiratory rate 20 times/min, temperature $37^{\circ} \mathrm{C}$. Head examination showed pale palpebral conjunctiva and a $\pm 10-\mathrm{cm}$ mass behind the right ear and pain.

The laboratory test result showed severe anemia, thrombocytopenia, increased blood urea nitrogen and serum creatinine level, and decreased albumin with proteinuria. In addition, RBC morphology showed rouleaux-like formation and bone marrow morphology showed total $66 \%$ clonal plasmacytes.

Laboratory tests carried out in this study consisted of hematological (Table 1), clinical chemistry (Table 2), urinalysis (Table 3), RBC morphology, bone marrow morphology, and protein electrophoresis during the patient stay.

Peripheral blood morphology showed bicytopenia with erythrocyte abnormalites, rouleaux-like formation, but no plasmacytes were found. Bone marrow morphology found 5\% plasmablast and $61 \%$ plasmacytes, while chemical staining with PAS showed diffuse weak and SBB showed negative result (Figure 2 and 3 ).
Peripheral Blood Morphology (31/01/2019)

Erythrocyte: Anisocytosis, dominant normocytes, microcyte, ovalocyte, teardrop cell, normochromic, rouleaux-like formation.

Leukocyte: Sufficient, elevated neutrophil, neutrophil with toxic granulation.

Thrombocyte: Reduced, even distribution, no clumps.

Result: $\quad$ Anemia with abnormal morphology of erythrocytes. Relative neutrophilia, neutrophil reactivity. Thrombocytopenia.

Conclusion: Bicytopenia was observed with abnormal morphology of erythrocyte with rouleaux-like formation.

Suggestion: Monitoring of RBC morphology. Investigation of bicytopenia causal factor. Total protein, albumin, globulin, calcium. Protein electrophoresis, Bence Jones protein.

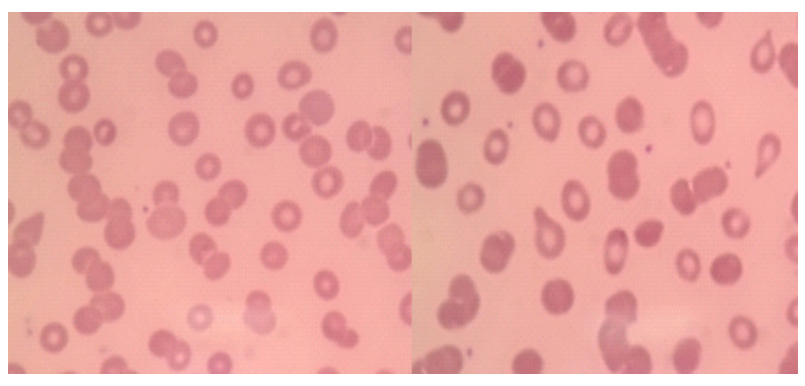

Figure 1. RBC morphology showed anisocytosis with rouleaux-like formation (Wright-Giemsa, $\mathrm{x} 1000)$

Table 1. Results of hematological tests

\begin{tabular}{lccccc}
\hline Parameter & $\mathbf{3 0 / 1 / 2 0 1 9}$ & $\mathbf{3 1 / 1 / 2 0 1 9}$ & $\mathbf{4 / 2 / 2 0 1 9}$ & $\mathbf{7 / 2 / 2 0 1 9}$ & Reference Range \\
\hline Erythrocyte (x10 $/ \mathrm{uL})$ & 1.07 & 1.04 & 3.83 & 3.77 & $4.00-5.40$ \\
Hemoglobin (g/dL) & 3.0 & 3.0 & 10.8 & 10.6 & $12-15$ \\
Hematocrit (\%) & 9.5 & 9.6 & 31.9 & 31 & $35-49$ \\
MCV (fL) & 88.8 & 92.3 & 83.3 & 82.2 & $80-94$ \\
MCH (gr) & 28 & 28.8 & 28.2 & 28.1 & $26-32$ \\
MCHC (gr\%) & 31.6 & 31.3 & 33.9 & 34.2 & $32-36$ \\
Leukocyte (/uL) & 5620 & 5160 & 6180 & 8.08 & $4,500-11,500$ \\
Trombocyte (/uL) & 114,000 & 122,000 & 85,000 & 74,000 & $150,000-450,000$ \\
Neutrophil (\%) & 72.5 & 74.2 & 69.7 & 64.7 & $50-70 \%$ \\
Lymphocyte (\%) & 18.9 & 18 & 18.8 & 22.8 & $18-42 \%$ \\
Monocyte (\%) & 7.7 & 6.4 & 8.6 & 9.9 & $2-11 \%$ \\
Eosinophil (\%) & 0.9 & 1.0 & 2.3 & 2.4 & $1.0-3.0 \%$ \\
Basophil (\%) & 0.0 & 0.4 & 0.6 & 0.2 & $0-2 \%$ \\
\end{tabular}


Table 2. Results of clinical chemistry tests

\begin{tabular}{lcccc}
\hline Parameter & $\mathbf{3 0 / 1 / 2 0 1 9}$ & $\mathbf{3 1 / 1 / 2 0 1 9}$ & $\mathbf{7 / 0 2 / 2 0 1 9}$ & Reference Range \\
\hline Albumin $(\mathrm{g} / \mathrm{dL})$ & 2.6 & & 2.93 & $3.97-4.94$ \\
SGOT/AST $(\mathrm{U} / \mathrm{L})$ & 11 & & & $\leq 32$ \\
SGPT/ALT $(\mathrm{U} / \mathrm{L})$ & 4 & & 37.4 & $\leq 33$ \\
BUN $(\mathrm{mg} / \mathrm{dL})$ & 51.5 & & 4.66 & $0.5-0.9$ \\
Creatinine $(\mathrm{mg} / \mathrm{dL})$ & 4.62 & & $80-140$ \\
Glucose $(\mathrm{mg} / \mathrm{dL})$ & 105 & & $136-145$ \\
Sodium $(\mathrm{mmol} / \mathrm{L})$ & 128 & & $3.5-5.1$ \\
Potassium $(\mathrm{mmol} / \mathrm{L})$ & 4.51 & & $98-107$ \\
Chloride $(\mathrm{mmol} / \mathrm{L})$ & 105.3 & & \\
Calcium $(\mathrm{mmol} / \mathrm{L})$ & 2.6 & 3.1 & \\
Bence Jones protein & & Negative & Negative \\
\hline
\end{tabular}

Table 3. Results of urinalysis

\begin{tabular}{lll}
\hline Urine Analyze & \multicolumn{1}{c}{ Result } & Reference Range \\
\hline Chemical & Negative $(<50 \mathrm{mg} / \mathrm{dL})$ & Negative \\
Glucose & $2+(100-299 \mathrm{mg} / \mathrm{dL})$ & Negative \\
Protein & Negative & Negative \\
Bilirubin & Normal $(2 \mathrm{mg} / \mathrm{dL})$ & Normal \\
Urobilinogen & 6.0 & $4.5-8.0$ \\
pH & 1.010 & $1.005-1.030$ \\
Density & $1+(20-59$ cell $/ \mathrm{uL})$ & Negative \\
Blood & Negative $(<5 \mathrm{mg} / \mathrm{dL})$ & Negative \\
Ketone & Negative & Negative \\
Nitrite & $3+(\geq 500$ cell/uL $)$ & Negative \\
Leukocyte esterase & Colorless & Colorless \\
Color & & \\
Sediment: & $86 / \mu \mathrm{L}$ & $0-25$ \\
Erythrocyte & $240 / \mu \mathrm{L}$ & $0-20$ \\
Leukocyte & $72.4 / \mu \mathrm{L}$ & $0-40$ \\
Epithelia & $1.1 / \mu \mathrm{L}$ & $0-1.2$ \\
Cylindrical structure & $2189.3 / \mu \mathrm{L}$ & $0-100$ \\
Bacteria & $365.6 / \mu \mathrm{L}$ & $0-10$ \\
Crystal & $0 / \mu \mathrm{L}$ & $0-25$ \\
Yeast-like cell & $5.5 / \mu \mathrm{L}$ & $0-6$ \\
Small round cell & $0.0 / \mu \mathrm{L}$ & $0-0.5$ \\
Pathlogical cylinder & $0.8 / \mu \mathrm{L}$ & $0-0.5$ \\
Mucus & $0.0 / \mu \mathrm{L}$ & $0-3$ \\
Sperm & $5.6 \mathrm{mS} / \mathrm{cm}$ & $3.1-27$ \\
Conductivity & &
\end{tabular}

\section{Bone Marrow Morphology}

Cellular density: Normocell, particle and fat globule were found.

Thrombopoietin: Sufficient, megakaryocytes were found.

Erythropoietic: $\mathrm{R}$ e d u c e d, 2 N R B C (polychromatophilic-acidophilic normoblast) were found.

Granulopoietic: Reduced, total 2\% stab and 14\% segmented neutrophils were found.
Others: Elevated plasmacyte, 5\% plasmablast, $61 \%$ plasmacyte (with most characteristic showed flame cell, varied size, margin oval/round/ irregular, low-to-mid N:C ratio, exentric/central/ irregular nucleus, rough chromatin, no nucleoli was found), $3 \%$ myeloma, $15 \%$ lymphocyte.

Result: $\quad 5 \%$ plasmablast and $61 \%$ plasmacyte were found. Reduced thrombopoietic, erythropoietic and granulopoietic. 
Conclusion: Current bone marrow puncture finding conclusive to multiple myeloma/ plasma cell myeloma diagnosis.

Suggestion: Monitor complete blood count and blood smear morphology. Total protein, serum albumin/globulin. Electrophoresis protein. Calcium, blood urea nitrogen, and serum creatinin. Skeletal survey.

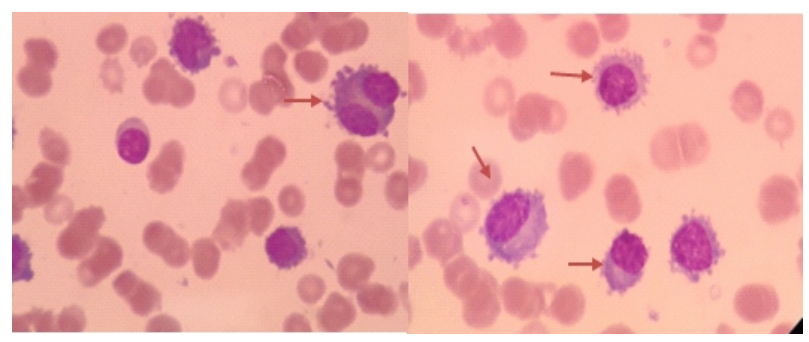

Figure 2. Bone marrow aspiration showed domination of plasmacyte with majority of flame cell, varied size, margin oval/round/irregular, low-to-mid $\mathrm{N}: \mathrm{C}$ ratio, exentric nucleus /central/ irregular, rough chromatin, no nucleoli was found (May Graunwald Giemsa, x1000)

\section{Cytochemical Staining}

Diffuse weak positive in Periodic Acid Schiff (PAS), negative in Sudan Black B (SBB) $\rightarrow$ plasmacyte

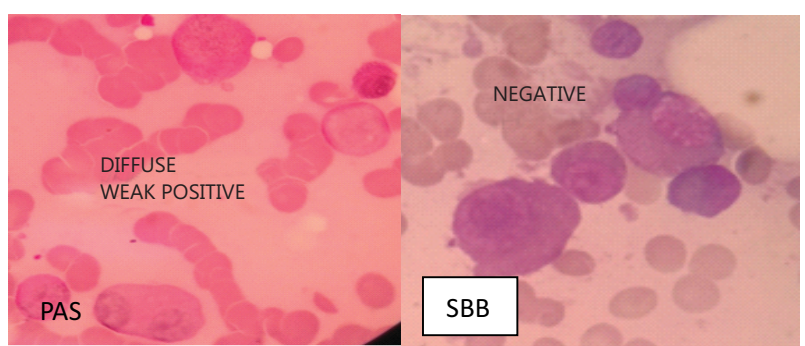

Figure 3. Cytochemical staining of plasma cell showed PAS (+) weak diffusion with SBB (-)

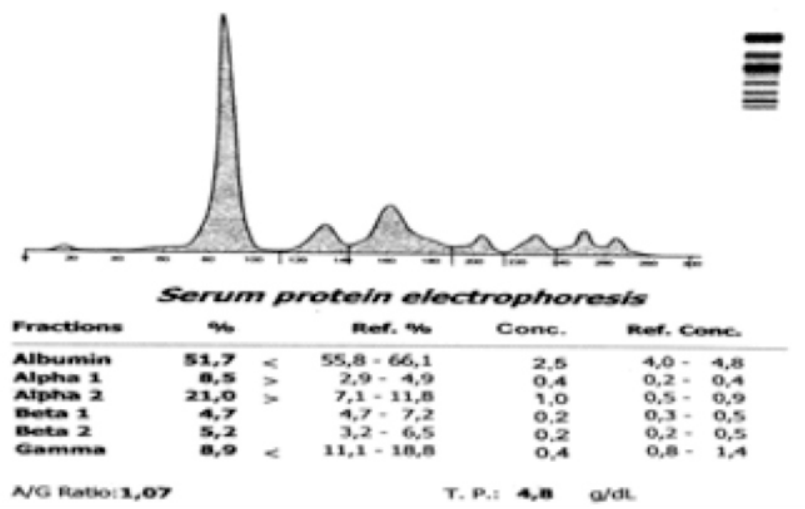

\section{Serum Protein Electrophoresis (SPE)}

Result: Reduced albumin fraction. Elevated alpha 1, alpha 2, globulin fraction. Reduced gamma globulin fraction.

Conclusion: Protein electrophoresis showed hypoalbumin and reduced globulin fraction, non-suggestive of $\mathrm{MM}$ (non-M-spike characteristic in MM).

\section{Radiological Examination}

Bone survey was carried out on $1^{\text {st }}$ February 2019 with multiple lytic lesion in calvaria, ossa costae, bilateral clavicle, bilateral scapule, bilateral humerus, femur, bilateral ischium, and bilateral illium. This finding aligned with $\mathrm{MM}$ findings. In lateral lumbosacral AP V.L 4 compression and VL 1-5 spondylosis was reported, in thorax PA osteolytic was observed in clavicula and bilateral scapula, which suggested malignancy.

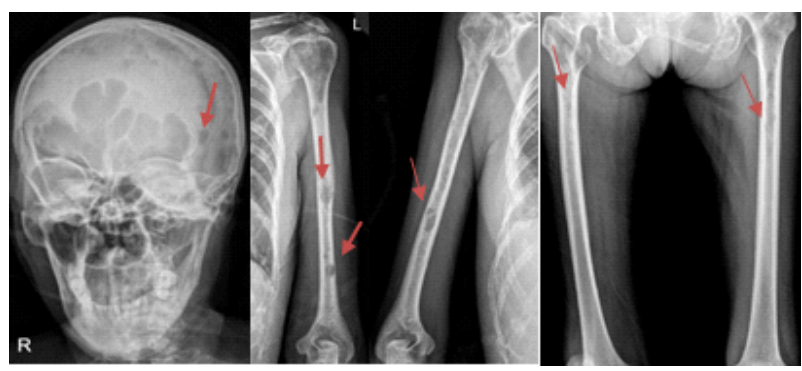

Figure 5. "Punched out" imaging and multiple osteolytic from sketelal survey

The patient was diagnosed with bicytopenia et causa multiple myeloma non-secretory, acute kidney injury and life-threatening normocytic normochromic anemia.

Figure 4. Serum Protein Electrophoresis (SPE) suggested hypoalbuminemia with hypogammaglobulinemia (left), SPE suggested hypoalbuminemia with monoclonal gammopathy M-spike (right) 


\section{DISCUSSION}

Multiple myeloma is a plasma cell malignancy, which is characterized by malignant proliferation of plasma cell in bone marrow. Monoclonal plasma cell proliferation, which is genetically mutated and accompanied with bone marrow environment triggers the cell to become neoplastic form. ${ }^{7}$ This malignancy could manifest as myeloma diffuse with systemic involvement (plasma cell myeloma or multiple myeloma), Monoclonal Gammopathy of Undeterminated Significance (MGUS), or as a variant of plasma cell myeloma, such as indolent myeloma, smoldering myeloma, osteosclerotic myeloma, plasma cell leukemia and multiple myeloma non-secretory. ${ }^{2,8}$

Measurement of monoclonal immunoglobulin in circulation is a gold standard for diagnosis, prognosis and management of MM. About 1-5\% of MM occurs without detection of MMNS type monoclonal protein, that clinical and radiological condition of patients matched MM symptoms, except in protein electrophoresis. ${ }^{7,9}$ Some experts limit MMNS as MM with no immunoglobulin or light chain secretion at all. ${ }^{10}$

To diagnose MM, International Myeloma Working Group (IMWG) guideline, which similar to Mayo Clinic guideline can be used. International myeloma working group guideline consists of three components as follows: $\geq 10 \%$ clonal plasmacyte in bone marrow), monoclonal protein in serum or urine except if MMNS is reported, and end-organ damage (CRAB) characterized by: hypercalcemia with calcium of $2.8 \mathrm{mg} / \mathrm{dL}$, renal insufficiency with creatinine $>1.73 \mathrm{mmol} / \mathrm{l}$ : normochromic-normocytic anemia with $\mathrm{Hb}>2 \mathrm{~g} / \mathrm{dL}$ under normal or $\mathrm{Hb}<10 \mathrm{~g} / \mathrm{dL}$, bone lesion or also known as lytic lesion, severe osteopenia or pathological fracture. ${ }^{11}$

In MMNS patients, diagnosis is established by finding of $30 \%$ plasmacyte in bone marrow or proven with biopsy of proved plasmacyte. This patient had multiple osteolytic. In $75 \%$ of MM patients, multiple lytic lesions in bone, fracture or osteoporosis were observed. ${ }^{12}$

Based on molecular mechanism, MMNS is classified into four categories, such as: oligosecretory, non-producer, true non-secretory, and false non-secretory multiple myeloma. ${ }^{13,14}$

Oligosecretory MM is characterized by $<1.0 \mathrm{~g} / \mathrm{dL}$ serum protein, urine protein $<100 \mathrm{mg} / \mathrm{hr}$, serum Free Light Chain (FLC) $<10 \mathrm{mg} / \mathrm{dL}$; non-producer $\mathrm{MM}$ is characterized by the absence of immunoglobulin (Ig); true non-secretory MM is multiple myeloma, which produces but not secrete Ig; whereas false non-secretory $\mathrm{MM}$ is characterized by measured intracellular Ig with immunofluorescence, but with no measured extracellular component(ex: Ig deposit in renal biopsy. ${ }^{13,14}$

Hematological tests revealed normocytic normochromic anemia with thrombocytopenia, blood morphology revealed rouleaux-like formation, which resulted from patient's $\mathrm{Hb}$ of $3 \mathrm{~g} / \mathrm{dL}$, clinical chemitsry tests showed hypoalbuminemia with normal albumin-globulin ratio was observed, elevated BUN and creatinine, and negative Bence Jones protein. Protein electrophoresis showed no elevation of monoclonal protein, with evidence not conclusive towards MM. Bone marrow puncture test showed elevated plasmacyte $(61 \%$, higher than normal plasmacyte count in bone marrow, which is less than $4 \%$ of all nucleated cells), skeletal survey showed "punched out" imaging with multiple osteolytic, which is conclusive for multiple myeloma. On that basis, MMNS was concluded.

In MMNS case, malignant plasma cells do not produce immunoglobulin, but they produce IL-6 cytokine, which activates Osteoclastic Activating Factor (OAF), which then reabsorbs bone with secreted protease, which in turns liquefy bone matrix and releases bone mineral to extracellular space, which results in bone destruction. This will result in elevated serum calcium, which causes pathological fracture and osteolytic imaging in patients with MM. In the patient in this study, hypercalcemia and multiple osteolytic with "punched out" morphology were observed.

Normocytic normochromic anemia manifestation on this patient was caused by normal bone marrow with plasmacyte infiltration, which reduces erythropoiesis by cytokine. Normocytic normochromic erythrocyte in this patient can be caused by chronic disease with no iron status test. A reduced renal function marked by elevated BUN and creatinine was caused by elevated calcium in the blood.

This case supports the previous case report about MMNS presented by Maimun et al. about MMNS case in male. ${ }^{15}$ The diagnosis was established based on multiple clinical findings and bone marrow puncture.

Unfortunately, SFLC, intracellular immunoglobulin with immunofluorescence and renal biopsy (immunoglobulin found in renal biopsy) was not performed to molecularly differentiate MM.

\section{CONCLUSION}

A case of MM was reported in a female with radiological and clinical findings suggesting "punched out" multiple osteolytic in skeletal 
survey and bone pain. Laboratory findings revealed hypercalcemia with anemia, low A/G ratio, elevated BUN and creatinine, elevated plasmacyte elevation in bone marrow without $\mathrm{M}$-spike in protein electrophoresis. To diagnose MMNS in this patient, SFLC, intracellular immunoglobulin and renal biopsy were still needed to differentiate MMNS based on molecular characteristics.

\section{REFERENCES}

1. Lonial BS, Kaufman JL. Non-secretory myeloma: A clinician 's guide Review, 2019; 4-7.

2. Wei A. Bone marrow immunohistology of plasma cell neoplasms. J Clin Pathol, 2003; 56(6): 406-11.

3. Aman AK. Profil penderita multiple myeloma di bagian Patologi Klinik FK USU/RSUP H. Adam Malik Medan. Maj Kedokt Nusant. 2005; 38(2): 176-9.

4. Ludwig H, Bolejack V, Crowley J, Bladé J, San Miguel J, et al. Survival and years of life lost in different age cohorts of patients with multiple myeloma. J Clin Oncol, 2010; 28(9): 1599-605.

5. Whicher JT, Davies JD, Grayburn JA. Intact and fragmented intracellular immunoglobulin in a case of non secretory myeloma. J Clin Pathol, 1975; 28(1): 54-9.

6. Middela S, Prakash K. Non-secretory multiple myeloma. Arch Pathol Lab Med, 2009; 43(4): 408-11.

7. Palumbo A, Anderson K. From multiple myeloma. N Engl J Med, 2010; 1-11.
8. Sharma A, Kaushal M, Chaturvedi NK, Yadav R. Cytodiagnosis of multiple myeloma presenting as orbital involvement: A case report. Cyto Journal, 2006; 3: 1-5.

9. Prasad R, Yadav RR, Singh A, Mathur SP, Mangal Y, Singh M. Non-secretory multiple myeloma presenting with diffuse sclerosis of affected bones interspersed with osteolytic lesions. Br J Radiol, 2009; 82(974): 29-31.

10. Caldas. Non-secretory myeloma or light chain-producing multiple myeloma: A case report. J Med Cases, 2011; 2(3): 97-100.

11. Kyle RA, Rajkumar S V. Criteria for diagnosis, staging, risk stratification and response assessment of multiple myeloma. Leukemia, 2009; 23(1): 3-9.

12. Rajkumar SV, Dimopoulos MA, Palumbo A, Blade J, Merlini G, et al. International myeloma working group updated criteria for the diagnosis of multiple myeloma. Lancet Oncol [Internet]. 2014;15(12): e538-48. Available from: http://dx.doi.org/10.1016/ S1470-2045(14)70442-5 (accessed 7 October, 2019).

13. Dupuis MM, Tuchman SA. Non-secretory multiple myeloma: From biology to clinical management. Onco Targets Ther, 2016; 9: 7583-90.

14. Corso A, Mangiacavalli S. Review articles non-secretory myeloma: Ready for a new definition?. Mediterr J Hematol Infect Dis [Internet]. 2017; 9(Mc): 2017053. Available from: www.mjhid.org (accessed 24 June, 2019).

15. Maimun Zulhaidah Arthamin, Nyi R. Wahidah BAS. Myeloma multiple non-secretory. Clin Pathol and Med Lab, 2012; 22(1): 99-103. 